\title{
Regulation of actin-binding protein ANLN by antitumor miR- 217 inhibits cancer cell aggressiveness in pancreatic ductal adenocarcinoma
}

\author{
Tetsuya Idichi' ${ }^{1}$, Naohiko Seki ${ }^{2}$, Hiroshi Kurahara ${ }^{1}$, Keiichi Yonemori ${ }^{1}$, Yusaku \\ Osako $^{1}$, Takayuki Arai ${ }^{2}$, Atsushi Okato${ }^{2}$, Yoshiaki Kita ${ }^{1}$, Takaaki Arigami ${ }^{1}$, Yuko \\ Mataki $^{1}$, Yuko Kijima ${ }^{1}$, Kosei Maemura ${ }^{1}$ and Shoji Natsugoe ${ }^{1}$ \\ ${ }^{1}$ Department of Digestive Surgery, Breast and Thyroid Surgery, Graduate School of Medical Sciences, Kagoshima University, \\ Kagoshima, Japan \\ ${ }^{2}$ Department of Functional Genomics, Chiba University Graduate School of Medicine, Chiba, Japan \\ Correspondence to: Naohiko Seki, email: naoseki@faculty.chiba-u.jp \\ Keywords: microRNA, miR-217, pancreatic ductal adenocarcinoma, ANLN, tumor-suppressor \\ Received: January 11, $2017 \quad$ Accepted: May 08, $2017 \quad$ Published: May 29, 2017 \\ Copyright: Idichi et al. This is an open-access article distributed under the terms of the Creative Commons Attribution License 3.0 \\ (CC BY 3.0), which permits unrestricted use, distribution, and reproduction in any medium, provided the original author and source \\ are credited.
}

\section{ABSTRACT}

Analysis of our microRNA (miRNA) expression signature of pancreatic ductal adenocarcinoma (PDAC) revealed that microRNA-217 (miR-217) was significantly reduced in cancer tissues. The aim of this study was to investigate the antitumor roles of $\boldsymbol{m i R}-217$ in PDAC cells and to identify miR-217-mediated molecular pathways involved in PDAC aggressiveness. The expression levels of $m i R-217$ were significantly reduced in PDAC clinical specimens. Ectopic expression of $m i R-217$ significantly suppressed cancer cell migration and invasion. Transcription of actin-binding protein Anillin (coded by $A N L N$ ) was detected by our in silico and gene expression analyses. Moreover, luciferase reporter assays showed that ANLN was a direct target of miR-217 in PDAC cells. Overexpression of $A N L N$ was detected in PDAC clinical specimens by real-time PCR methods and immunohistochemistry. Interestingly, Kaplan-Meier survival curves showed that high expression of ANLN predicted shorter survival in patients with PDAC by TCGA database analysis. Silencing ANLN expression markedly inhibited cancer cell migration and invasion capabilities of PDAC cell lines. We further investigated ANLNmediated downstream pathways in PDAC cells. "Focal adhesion" and "Regulation of actin binding protein" were identified as ANLN-modulated downstream pathways in PDAC cells. Identification of antitumor miR-217/ANLN-mediated PDAC pathways will provide new insights into the potential mechanisms underlying the aggressive course of PDAC.

\section{INTRODUCTION}

Due to the aggressive nature of pancreatic ductal adenocarcinoma (PDAC), it is one of the most lethal malignancies in the world [1,2]. Recently developed targeted molecular strategies have not contributed to improved therapies for PDAC, and the 5-year survival rate after diagnosis is only $5 \%[2,3]$. More than $50 \%$ of patients develop local recurrence or distant metastasis after curative resection. PDAC frequently metastasizes to the liver, peritoneum and lung $[4,5]$. We hypothesized that current genomic approaches might be used to elucidate the molecular mechanisms underlying PDAC metastasis and suggest improved treatments for this disease. microRNA (miRNA) belongs to a family of small non-coding RNAs that fine-tune the expression of protein coding/noncoding RNAs by repressing translation or cleaving RNA transcripts in a sequence-dependent manner [6]. A unique characteristic of human miRNAs is that a single miRNA species can regulate a large number of RNA transcripts [7, 8]. Therefore, dysregulated miRNAs can disrupt tightly controlled RNA networks and promote 
cancer cell metastasis. At present, numerous studies have indicated that miRNAs are aberrantly expressed in several cancers, including PDAC [9-11]. The discovery of miRNAs and subsequent studies have deepened our understanding of the roles of miRNA in human cancer pathogenesis $[12,13]$.

Using miRNA expression signatures, we have identified antitumor miRNAs that modulate novel cancer networks in several types of cancer [14-16]. More recently, we reported the anti-tumor function of $m i R-375$, and the observation that it regulated oncogenic zinc finger protein 36 ring finger protein-like 2 (ZFP36L2) in PDAC cells [17]. Moreover, ZFP36L2 was overexpressed in PDAC specimens and Kaplan-Meier survival curves showed that high expression of ZFP36L2 predicted shorter survival in PDAC patients [17]. We have also constructed an miRNA expression signature of PDAC clinical specimens based on RNAsequencing. Our data showed that $m i R-217$ was significantly downregulated in PDAC tissues, suggesting that it functions as an antitumor miRNA that targeted several oncogenic genes in PDAC cells. Past studies demonstrated that miR-217 acts as an antitumor miRNA in several types of cancer [18-20]. $m i R-217$ expression was observed to be negatively correlated with KRAS protein expression in PDAC cell lines and $m i R$ 217 directly regulated $K R A S[21,22]$. However, the RNA networks mediated by $m i R-217$ in PDAC are still obscure.

The aim of this study was to investigate the antitumor roles of $m i R-217$ in PDAC cells and to identify $m i R-217-$ mediated molecular pathways involved in PDAC aggressiveness. Our present data showed that the actinbinding protein anillin (ANLN) (coded by the $A N L N$ gene) was directly regulated by antitumor $m i R-217$ in PDAC cells. Kaplan-Meier survival curves showed that high expression of $A N L N$ predicted shorter survival in patients. Moreover, we showed that "Focal adhesion" and "Regulation of actin binding protein" were downstream pathways modulated by ANLN protein in PDAC cells. Elucidation of antitumor miR-217-mediated molecular networks in PDAC may provide new insights into the potential mechanisms of PDAC aggressiveness.

\section{RESULTS}

\section{Expression levels of $m i R-217$ in PDAC specimens and cell lines}

We evaluated expression levels of $m i R-217$ in PDAC tissues $(\mathrm{n}=27)$, normal pancreatic tissues $(\mathrm{n}=14)$ and two PDAC cell lines (PANC-1 and SW1990). The clinical samples' backgrounds and clinicopathological characteristics are summarized in Table 1A. Normal pancreatic tissues are summarized in Table 1B. The expression levels of $m i R-217$ were significantly lower in tumor tissues compared with normal pancreatic tissues $(P<0.0001$, Figure 1A, Supplementary Figure 1). However, there were no significant relationships between any of the clinicopathological parameters, (i.e., neoadjuvant chemotherapy, metastasis or recurrence) and the expression of $m i R-217$ (data not shown).

\section{Effect of $m i R-217$ expression on cell growth, migration and invasiveness in PDAC cell lines}

To investigate the functional roles of $m i R-217$, we performed gain-of-function studies using transfection of PANC-1 and SW1990 cells. The expression levels of $m i R$ 217 were markedly lower in two cell lines (Figure 1A). To elucidate molecular mechanisms of low expression of miR-217 in PDAC cells, PANC-1 and SW1990 cells were treated with the demethylating agent [5-aza-2'deoxycytidine (5-aza-dC)]. Expression levels of $m i R-217$ in PDAC cells were significantly elevated by 5 -aza-dc treatment (Supplementary Figure 2). These data suggested that DNA methylation might cause silencing of $m i R-217$ in PDAC cells.

XTT assays revealed no significant inhibition of cell proliferation in PANC-1 or in SW1990 cells transfected with miR-217 in comparison with mock or control transfectants (Figure 1B). In vitro assays demonstrated that migration and invasion were significantly inhibited in miR-217 transfectants compared with mock or miRcontrol transfectants (each, $P<0.0001$, Figure 1C and 1D, Supplementary Figure 5). These results suggested that $m i R-217$ could have an antitumor function in PDAC cells.

\section{Identification of candidate genes regulated by $m i R-217$ in PDAC cells}

To gain further insight into the molecular mechanisms and pathways regulated by tumor-suppressive miR-217 in PDAC cells, we used in silico analyses. The strategy for narrowing down the genes targeted by $m i R-217$ is shown in Figure 2. The TargetScan database showed that 3,970 genes have putative target sites for $m i R$ 217 in their 3'-UTRs. Gene expression data showed that 996 genes were upregulated (fold-change $\log _{2}>1.5$ ) in cancer tissues by GEO database analyses (GEO accession number; GSE15471). We identified 167 genes that were putative targets of $m i R-217$ and were upregulated in PDAC specimens. Finally, we found that 19 genes had conserved sequences that were putatively targeted by $m i R$ 217 (Table 2).

We also checked the expression status of those 19 genes and the clinical significance of PDAC by using the OncoLnc database (http://www.oncolnc.org/). KaplanMeier survival curves showed that high expression of 6 genes was associated with poor prognosis in PDAC by TCGA database searching (Table 2, Supplementary Figure 3). In this study, we focused on the actin binding protein anillin (ANLN) because past studies had indicated that actin binding proteins were involved in metastasis [23-26]. 
Table 1A: Patient characteristics

\section{Pancreatic ductal adenocarcinoma (PDAC)}

Total number

Average age (range), years

Gender

T category

$\mathrm{N}$ category

M category

Neoadjuvant chemotherapy

Recurrence
(\%)

\section{7}

$67.1(42-85)$

12

15

Female

pTis

pT1

pT2

pT3

pT4

0

1

0

1

$(-)$

$(+)$

$(-)$

$(+)$
15

12

25

2

12

15

7

20

Table 1B: Patient characteristics

\section{Normal pancreatic tissue}

Total number

Average age (range), years

Gender

\begin{tabular}{lc} 
& $63.8(42-85)$ \\
Male & 6 \\
Female & 8 \\
\hline
\end{tabular}

14

8

\section{$A N L N$ is a direct target of $m i R-217$ in PDAC cells}

We performed qRT-PCR to validate $m i R-217$ repression of $A N L N$ mRNA expression in PDAC cell lines. Our studies revealed that $A N L N$ mRNA was significantly reduced in $m i R-217$ transfectants in comparison with mock or miR-control transfectants $(P<0.0001$ and $P<0.0001$, Figure 3A). Expression of ANLN protein was also repressed in the miR-217 transfectants (Figure 3B, Supplementary Figure 6).

Target prediction databases indicated two putative target sites in the 3'-UTR of ANLN (Figure 3C). To determine whether $A N L N$ mRNA had a functional target site, we performed a dual luciferase reporter assay. We used vectors encoding the partial wild-type sequence of the3'-UTR of the mRNA, including the predicted $m i R-217$ target sites. We found that the luminescence intensity was significantly reduced by co-transfection with miR-217 and the vector carrying the wild-type 3'UTR (position 132 - 139), whereas transfection with the deletion vector (binding site had been removed) blocked the decrease in luminescence $(P<0.005$, Figure $3 C)$. In contrast, the luminescence intensity was not decreased in co-transfection with $m i R-217$ and the vector carrying the wild-type 3'-UTR (position 660 - 666) (Figure 3C).

\section{Effects of silencing $A N L N$ on PDAC cell lines}

To investigate the functional role of $\mathrm{A} N L N$ in PDAC cells, we carried out loss-of-function studies using si- $A N L N$ transfectants. First, we evaluated the knockdown efficiency of si- $A N L N$ transfection in PDAC cell lines. In the present study, we used two types of si- $A N L N$ (si- $A N L N-1$ and si- $A N L N-2)$. Based on qRT-PCR assessment and Western blot analyses, 

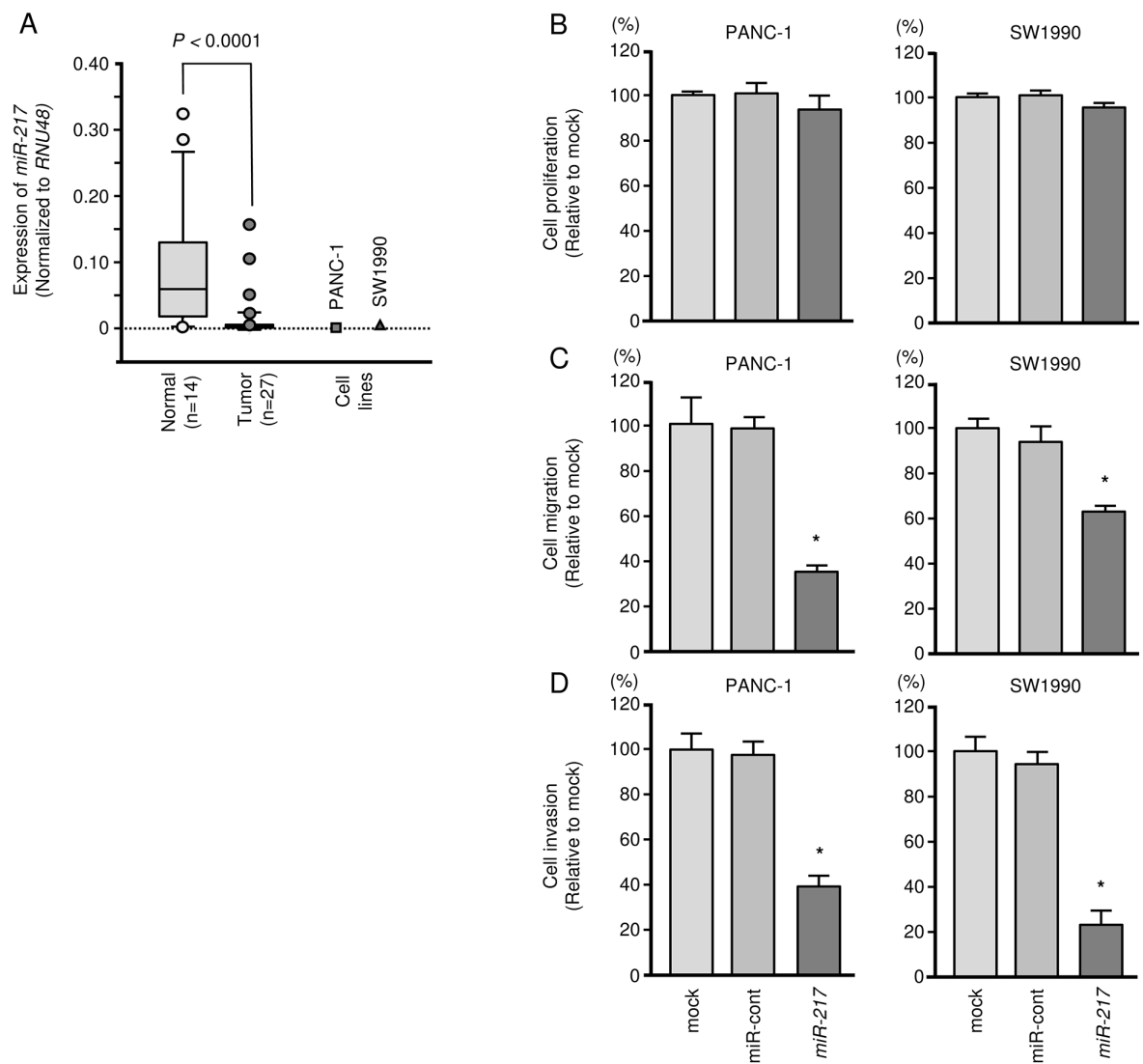

Figure 1: Antitumor functions of $\mathbf{m i R}-217$ in PDAC cell lines (PANC-1 and SW1990). (A) Expression levels of $m i R$-217 in PDAC clinical specimens and cell lines were determined by qRT-PCR. Data were normalized to RNU48 expression. (B) Cell proliferation was determined by XTT assays $72 \mathrm{~h}$ after transfection with $10 \mathrm{nM} \mathrm{miR-217.} \mathrm{*,} P<0.0001$. (C) Cell migration activity was determined by migration assays. ${ }^{*}, P<0.0001$. (D) Cell invasion activity was determined using Matrigel invasion assays. ${ }^{*}, P<0.0001$.

\begin{tabular}{|c|}
\hline $\begin{array}{c}\text { Identification of } \\
\text { putative target genes } \\
\text { of miR-217 } \\
\text { TargetScan database } 7.1 \\
(3,970 \text { genes })\end{array}$ \\
\hline+ \\
\hline $\begin{array}{c}\text { Gene expression analysis } \\
\text { (GEO; GSE15471) } \\
\text { Upregulated in PDAC tissues } \\
\text { (996 genes) }\end{array}$ \\
$\qquad$ \\
\hline $\begin{array}{c}\text { Candidate target genes } \\
\text { regulated by miR-217 } \\
\text { (167 genes) } \\
\text { (19 genes have conserved sites) } \\
\text { (Table } 2)\end{array}$ \\
\hline
\end{tabular}

Figure 2: The strategy for analysis of $\mathbf{m i R}-217$ target genes. Flow chart illustrates the strategy for analysis of $m i R-217$ target genes in PDAC cells. 
Table 2: Candidate target genes regulated by miR-217

\begin{tabular}{|c|c|c|c|c|c|c|c|c|}
\hline \multirow[t]{2}{*}{ Entrez gene } & \multirow[t]{2}{*}{ Gene symbol } & \multirow[t]{2}{*}{ Gene name } & \multicolumn{4}{|c|}{ Conserved sites } & \multirow{2}{*}{$\frac{\text { GEO data }}{\text { FC }(\log 2)}$} & \multirow{2}{*}{$\frac{\text { *TCGA_OncoLnc }}{\text { P-value }}$} \\
\hline & & & 8mer sites & 7 mer-m8 sites & $7 \mathrm{mer}-\mathrm{A} 1$ sites & Total & & \\
\hline 9644 & $S H 3 P X D 2 A$ & SH3 and PX domains $2 \mathrm{~A}$ & 1 & 1 & 1 & 3 & 1.631 & 0.3620 \\
\hline 54443 & $A N L N$ & anillin, actin binding protein & 1 & 1 & 0 & 2 & 1.729 & 0.0014 \\
\hline 3624 & $I N H B A$ & inhibin, beta A & 0 & 1 & 0 & 1 & 5.190 & 0.0414 \\
\hline 1295 & COL8A1 & collagen, type VIII, alpha 1 & 1 & 0 & 0 & 1 & 4.623 & 0.3640 \\
\hline 2335 & FN1 & fibronectin 1 & 0 & 1 & 0 & 1 & 3.727 & 0.0950 \\
\hline 860 & $R U N X 2$ & runt-related transcription factor 2 & 1 & 0 & 0 & 1 & 2.932 & 0.4790 \\
\hline 10085 & EDIL3 & $\begin{array}{l}\text { EGF-like repeats and discoidin I-like } \\
\text { domains } 3\end{array}$ & 1 & 0 & 0 & 1 & 2.560 & 0.5300 \\
\hline 6400 & SEL1L & $\begin{array}{l}\text { sel-1 suppressor of lin-12-like (C. } \\
\text { elegans) }\end{array}$ & 1 & 0 & 0 & 1 & 2.375 & 0.0950 \\
\hline 22943 & $D K K 1$ & $\begin{array}{l}\text { dickkopf WNT signaling pathway } \\
\text { inhibitor } 1\end{array}$ & 0 & 0 & 1 & 1 & 2.303 & 0.0110 \\
\hline 800 & $C A L D 1$ & caldesmon 1 & 0 & 0 & 1 & 1 & 2.067 & 0.5440 \\
\hline 10630 & $P D P N$ & podoplanin & 0 & 1 & 0 & 1 & 1.957 & 0.3500 \\
\hline 79070 & $K D E L C 1$ & $\begin{array}{l}\text { KDEL (Lys-Asp-Glu-Leu) containing } \\
1\end{array}$ & 1 & 0 & 0 & 1 & 1.870 & 0.0969 \\
\hline 55454 & CSGALNACT2 & $\begin{array}{l}\text { chondroitin sulfate } \\
\text { N-acetylgalactosaminyltransferase } 2\end{array}$ & 0 & 1 & 0 & 1 & 1.781 & 0.6930 \\
\hline 57181 & SLC39A10 & $\begin{array}{l}\text { solute carrier family } 39 \text { (zinc } \\
\text { transporter), } \\
\text { member } 10\end{array}$ & 0 & 1 & 0 & 1 & 1.770 & 0.0007 \\
\hline 6091 & $\mathrm{ROBOI}$ & $\begin{array}{l}\text { roundabout, axon guidance receptor, } \\
\text { homolog } 1 \text { (Drosophila) }\end{array}$ & 0 & 0 & 1 & 1 & 1.769 & 0.8790 \\
\hline 22856 & CHSY1 & chondroitin sulfate synthase 1 & 0 & 0 & 1 & 1 & 1.652 & 0.3330 \\
\hline 23603 & COROIC & coronin, actin binding protein, $1 \mathrm{C}$ & 0 & 0 & 1 & 1 & 1.566 & 0.0056 \\
\hline 50515 & CHST11 & $\begin{array}{l}\text { carbohydrate (chondroitin 4) } \\
\text { sulfotransferase } 11\end{array}$ & 1 & 0 & 0 & 1 & 1.559 & 0.0024 \\
\hline 9444 & $Q K I$ & $\begin{array}{l}\text { QKI, KH domain containing, RNA } \\
\text { binding }\end{array}$ & 0 & 0 & 1 & 1 & 1.554 & 0.9170 \\
\hline
\end{tabular}

*Kaplan-Meier analysis log-rank P-value $<0.05$

Poor prognosis with a high expression

both siRNAs effectively downregulated ANLN expression in both cell lines $(P<0.0001$, Figure 4A and 4B). XTT, cell migration and cell invasion assays demonstrated that cell proliferation, migration and invasion were inhibited in si- $A N L N$ transfectants compared with mock- or siRNA-control-transfected cells (Figure 4C, 4D and 4E).

\section{Effects of cotransfection of $A N L N$ and $m i R-217$ in PDAC cell line}

To confirm the antitumor effect of $m i R-217$ by targeting $A N L N$ in PDAC cells, we performed rescue experiments by $A N L N$ overexpression in PANC-1 cells with $m i R-217$ restoration. The rescue studies indicated that cell migration and invasion properties were rescued by $A N L N$ transfectants compared with cells with restored $m i R-217$ only (Supplementary Figure 4). These data indicated that $A N L N$ expression was regulated by $m i R-217$ and expression of $m i R-217$ was induced antitumor effects of migration and invasion in PDAC cells.

\section{Expression of $A N L N$ in PDAC clinical specimens and the TCGA database}

$A N L N$ was upregulated in clinical PDAC samples and cell lines, PANC-1 and SW1990 $(P<0.0001$, Figure 5A). Negative correlations between miR-217 expression and $A N L N$ mRNA expression were found using Spearman's rank test $(R=-0.841, P<0.0001$, Figure 5B). 
Using a PDAC TCGA database, we found that the mRNA expression levels of $A N L N$ were significantly upregulated. The $A N L N$ high expression group had a significantly poorer overall survival by Kaplan-Meier analysis (Log-rank $P$-value $=0.00142$, Figure 5C).

We confirmed the expression of ANLN protein in PDAC clinical specimens using immunohistochemistry. A total of 27 specimens were evaluated. All tumors were of the differentiated adenocarcinoma type (well, moderately, poorly) and showed strong nuclear immunoreactivity (Figure 5D).

\section{Investigation of downstream genes regulated by $A N L N$ in PDAC cells}

To identify the downstream genes regulated by $A N L N$, genome-wide gene expression and in silico analyses were performed in a PDAC cell line (PANC-1) transfected with si- $A N L N$. Our selection strategy is shown in Figure 6. A total of 937 genes were commonly downregulated $\left(\log _{2}\right.$ ratio $\left.<-1.0\right)$ in si- $A N L N$-transfected PANC-1 cells. We also assessed the downregulated genes using KEGG pathways and the GENECODIS program. With that approach, we identified 8 pathways and 15 genes that were significantly enriched (Table $3 \mathrm{~A}$ and $3 \mathrm{~B}$ ). Our microarray expression data was deposited in Gene Expression Omnibus (GEO) database (accession number; GSE93290).

Furthermore, we checked the expression status of those genes and their pathologic relations to PDAC by using the TCGA-based large cohort study data. KaplanMeier analysis showed that high expression group of 6 genes (ITGA3, GNA15, PLAU, FZD2, MSM and

Positions 132-139 of ANLN 3' UTR
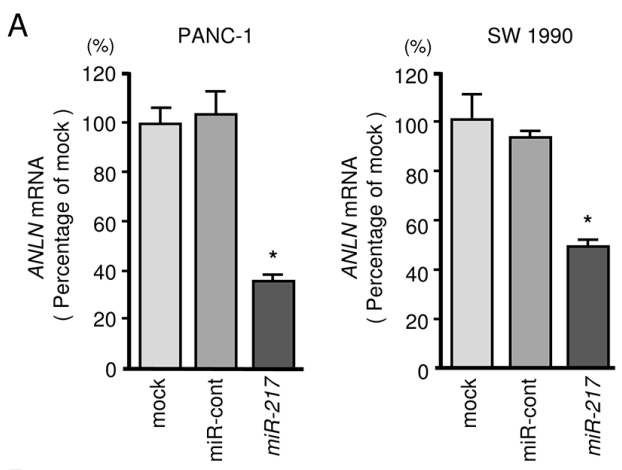

B

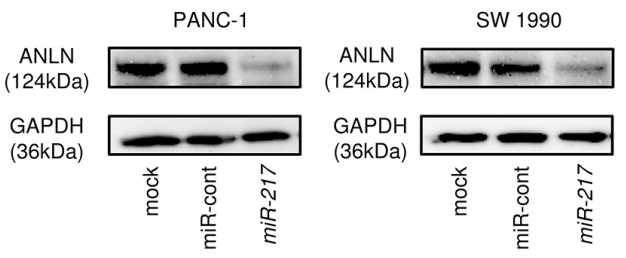

C

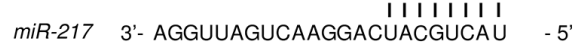

ANLN-Deletion 5'- UAUUCACUACGUAUU - . - . - . - - UU - 3'

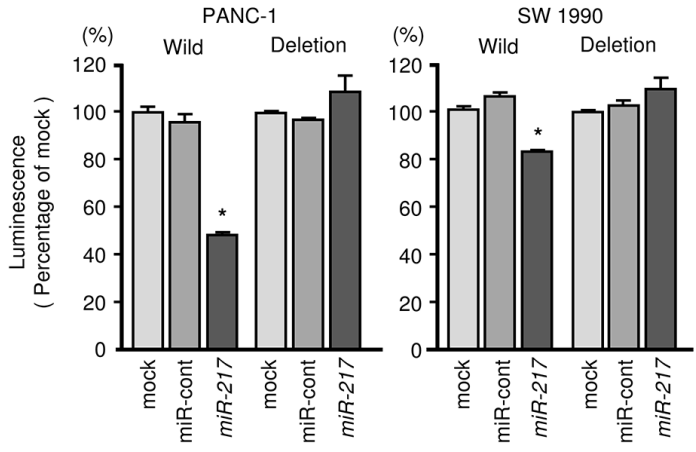

Positions 660-666 of ANLN 3' UTR

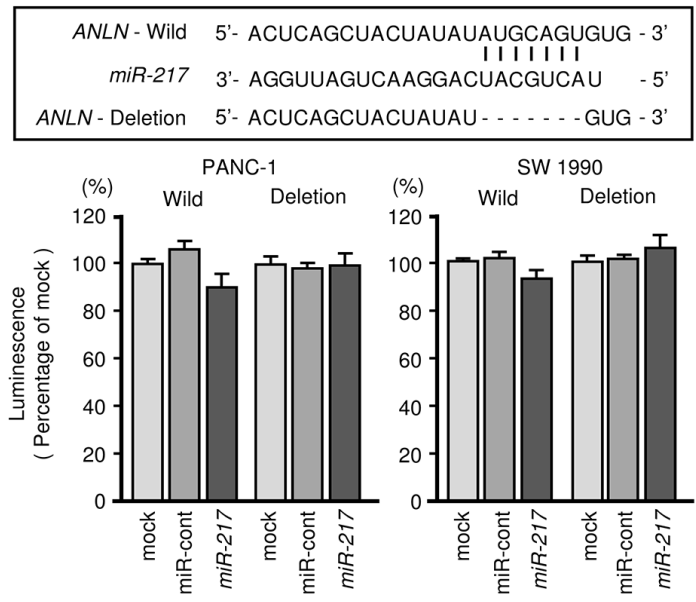

Figure 3: Direct regulation of $\boldsymbol{A N L N}$ by $\boldsymbol{m i R}$-217 in PDAC cell lines. (A) $A N L N$ mRNA expression in PDAC cell lines was evaluated by qRT-PCR $72 \mathrm{~h}$ after transfection with $m i R-217$. GUSB was used as an internal control. *, $P<0.0001$. (B) ANLN protein expression in PDAC cell lines was evaluated by Western blot analyses $96 \mathrm{~h}$ after transfection with $m i R-217$. GAPDH was used as a loading control. (C) miR-217 binding sites in the 3'-UTR of $A N L N$ mRNA. Dual luciferase reporter assays using vectors encoding putative miR-217 (positions 132 - 139 or 660 - 666) target sites of the $A N L N 3^{\prime}$-UTR for both wild-type and deleted regions. Normalized data were calculated as ratios of Renilla/firefly luciferase activities. * $P<0.005$. 
Table 3A: Enriched KEGG pathways in si-ANLN transfectant

\begin{tabular}{lllcl}
\hline KEGG ID & \multicolumn{1}{c}{ Pathways } & P-value & No.of genes & \multicolumn{1}{c}{ Genes } \\
\hline Kegg:04510 & Focal adhesion & 0.00011 & 5 & ITGA3,RAC2,FLNA,LAMC2,MYL9 \\
Kegg:05200 & Pathways in cancer & 0.00105 & 5 & ITGA3,RAC2,FZD1,FZD2,LAMC2 \\
Kegg:04512 & ECM-receptor interaction & 0.00005 & 4 & ITGA3,HSPG2,LAMC2,CD47 \\
Kegg:04810 & $\begin{array}{l}\text { Regulation of actin } \\
\text { cytoskeleton }\end{array}$ & 0.00156 & 4 & ITGA3,RAC2,MSN,MYL9 \\
Kegg:04670 & $\begin{array}{l}\text { Leukocyte transendothelial } \\
\text { migration }\end{array}$ & 0.00013 & 3 & RAC2,MSN,MYL9 \\
Kegg:04610 & $\begin{array}{l}\text { Complement and } \\
\text { coagulation cascades }\end{array}$ & 0.00050 & 3 & F8,SERPINE1,PLAU \\
Kegg:04310 & Wnt signaling pathway & 0.00050 & 3 & RAC2,FZD1,FZD2 \\
Kegg:05146 & Amoebiasis & 0.00186 & 3 & SERPINB9,LAMC2, GNA15 \\
\hline
\end{tabular}

Table 3B: Downregulated genes by si-ANLN transfectant in enrichied KEGG pathways

\begin{tabular}{|c|c|c|c|c|c|c|}
\hline \multirow{2}{*}{$\begin{array}{l}\text { Entrez gene } \\
\text { ID }\end{array}$} & \multirow[t]{2}{*}{ Gene symbol } & \multirow[t]{2}{*}{ Gene name } & \multirow[t]{2}{*}{ miR-217 target sites } & \multicolumn{2}{|c|}{ Expression FC(log2) } & \multirow{2}{*}{$\begin{array}{l}\begin{array}{c}* \text { TCGA } \\
\text { OncoLnc }\end{array} \\
\text { P-value }\end{array}$} \\
\hline & & & & $\begin{array}{l}\text { mock vs si- } \\
\qquad A N L N\end{array}$ & GEO & \\
\hline 8321 & $F Z D 1$ & frizzled class receptor 1 & 0 & -1.603 & 1.186 & 0.2750 \\
\hline 10398 & MYL9 & myosin, light chain 9 , regulatory & 0 & -1.536 & 2.181 & 0.9090 \\
\hline 961 & $C D 47$ & CD47 molecule & 0 & -1.511 & 1.236 & 0.0705 \\
\hline 5880 & $R A C 2$ & $\begin{array}{l}\text { ras-related C3 botulinum toxin substrate } \\
2 \text { (rho family, small GTP binding protein } \\
\text { Rac2) }\end{array}$ & 0 & -1.444 & 1.323 & 0.7490 \\
\hline 3918 & $L A M C 2$ & laminin, gamma 2 & 0 & -1.436 & 2.761 & 0.0595 \\
\hline 3675 & $I T G A 3$ & $\begin{array}{l}\text { integrin, alpha } 3 \text { (antigen CD } 49 \text { C, alpha } 3 \\
\text { subunit of VLA-3 receptor) }\end{array}$ & 0 & -1.363 & 1.329 & 0.0004 \\
\hline 2316 & FLNA & filamin A, alpha & 0 & -1.332 & 1.426 & 0.3290 \\
\hline 2769 & GNA15 & $\begin{array}{l}\text { guanine nucleotide binding protein (G } \\
\text { protein), alpha } 15 \text { (Gq class) }\end{array}$ & 0 & -1.309 & 1.089 & 0.0070 \\
\hline 5328 & $P L A U$ & plasminogen activator, urokinase & 1 & -1.252 & 2.341 & 0.0052 \\
\hline 2535 & FZD2 & frizzled class receptor 2 & 0 & -1.243 & 1.295 & 0.0349 \\
\hline 3339 & $H S P G 2$ & heparan sulfate proteoglycan 2 & 0 & -1.177 & 1.080 & 0.3290 \\
\hline 5272 & SERPINB9 & $\begin{array}{l}\text { serpin peptidase inhibitor, clade B } \\
\text { (ovalbumin), member } 9\end{array}$ & 1 & -1.111 & 1.670 & 0.3210 \\
\hline 4478 & $M S N$ & moesin & 1 & -1.068 & 1.740 & 0.0389 \\
\hline 5054 & SERPINE1 & $\begin{array}{l}\text { serpin peptidase inhibitor, clade E (nexin, } \\
\text { plasminogen activator inhibitor type } 1 \text { ), } \\
\text { member } 1\end{array}$ & 0 & -1.060 & 1.966 & 0.0066 \\
\hline 2157 & $F 8$ & $\begin{array}{l}\text { coagulation factor VIII, procoagulant } \\
\text { component }\end{array}$ & 0 & -1.021 & 1.110 & 0.3080 \\
\hline
\end{tabular}

*Kaplan-Meier analysis log-rank P-value $<0.05$

Poor prognosis with a high expression 

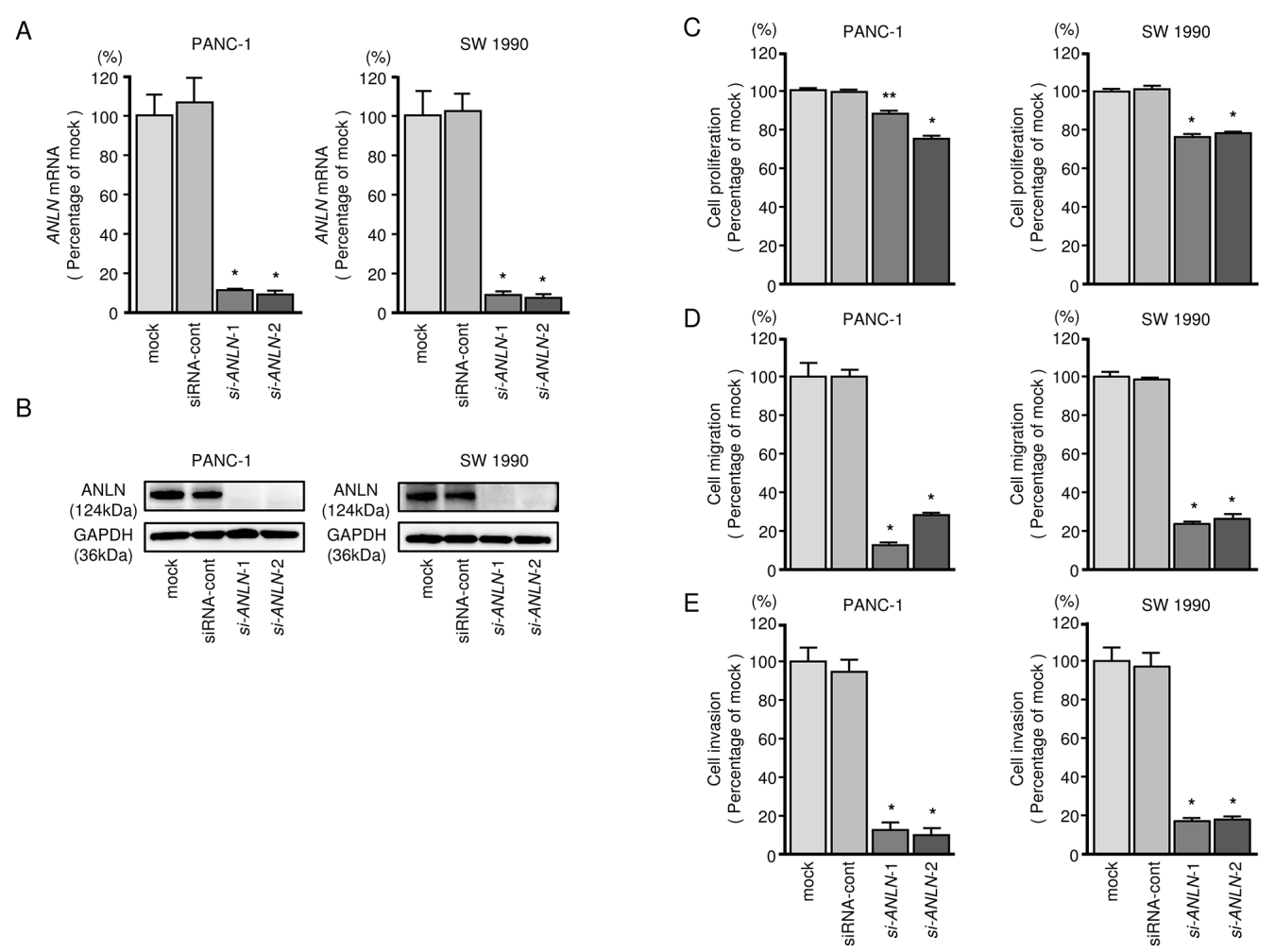

Figure 4: $A N L N$ mRNA and ANLN protein expression after si-ANLN transfection and effects of $A N L N$ silencing in PDAC cell lines. (A) $A N L N$ mRNA expression in PDAC cell lines was evaluated by qRT-PCR $72 \mathrm{~h}$ after transfection with $s i-A N L N-1$ or $s i-A N L N-2$. GUSB was used as an internal control. (B) ANLN protein expression in PDAC cell lines was evaluated by Western blot analysis $96 \mathrm{~h}$ after transfection with $m i R-217$. GAPDH was used as a loading control. (C) Cell proliferation was determined with the XTT assays $72 \mathrm{~h}$ after transfection with $10 \mathrm{nM} s i-A N L N-1$ or $s i-A N L N-2$. *, $P<0.0001$, **, $P<0.05$. (D) Cell migration activity was determined by migration assays. *, $P<0.0001$. (E) Cell invasion activity was determined using Matrigel invasion assays. *, $P<0.0001$.
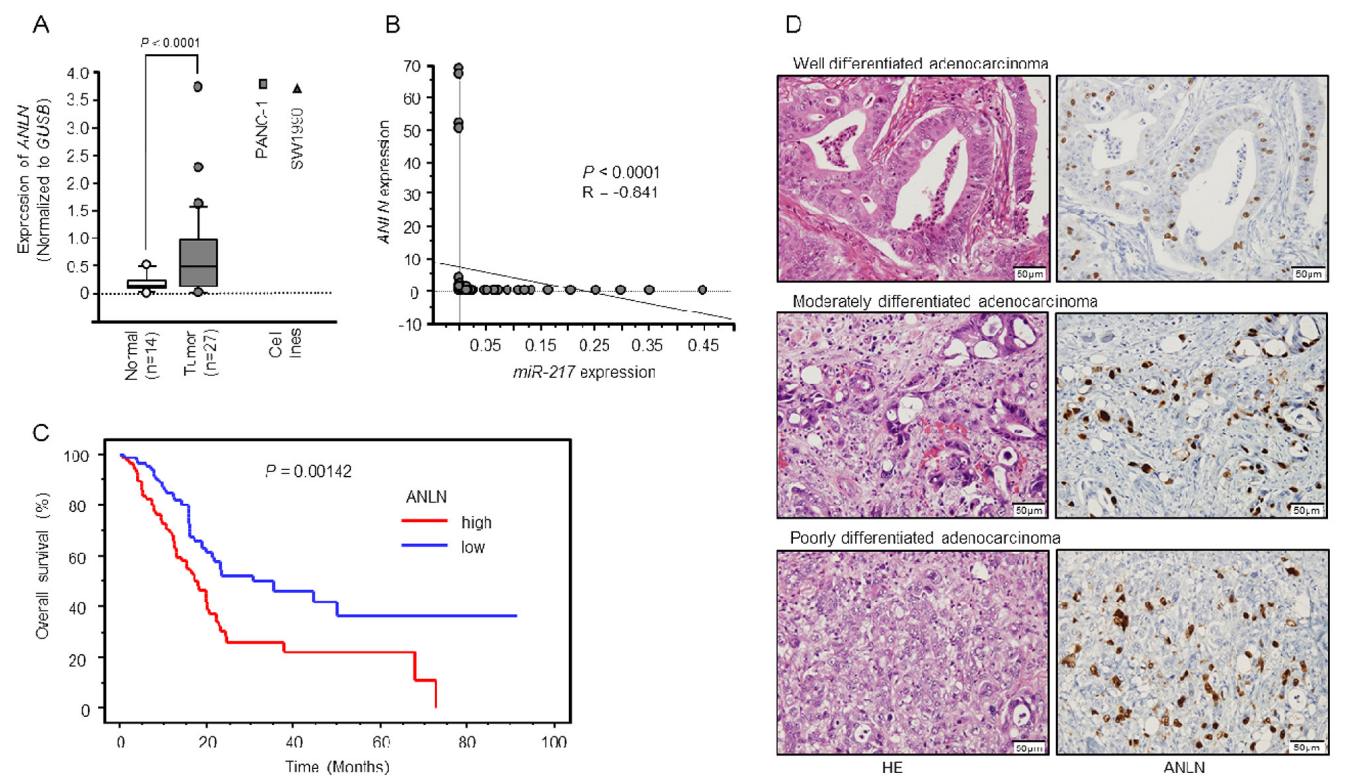

Figure 5: Expression levels of $A N L N$ mRNA and immunohistochemical staining of ANLN protein in PDAC specimens. (A) Expression levels of $A N L N$ mRNA in PDAC or normal pancreatic tissues and PDAC cell lines. (B) The expression levels of miR-217 and $A N L N$ were negatively correlated $(R=-0.841, \mathrm{P}<0.0001)$. (C) Kaplan-Meier curve analysis of overall patient survival between those with high $A N L N$ expression and low $A N L N$ expression in the PDAC TCGA database. (D) Immunohistochemical staining of ANLN in PDAC specimens. All differentiated types of PDAC (well, moderately, poorly) showed strong nuclear immunoreactivity (Left panel: hematoxylin-eosin staining, Right panel: ANLN staining, original magnification, X400). 
SERPINE1) had a significantly poorer overall survival for patients with PDAC (Table 3B and Figure 7).

\section{DISCUSSION}

In this study, we confirmed the downregulation and antitumor function of $m i R-217$ in PDAC cells, showing that miR-217 inhibited cancer cell migration and invasion. Based on those findings, we hypothesized that $m i R-217$ suppressed novel metastatic pathways in PDAC cells. In human genome, $m i R-217$ is located on the human chromosome $2 \mathrm{q} 16.1$ region and $m i R-217$ forms miRNA cluster with $m i R-216 s$ (miR-216a,miR-216b). Expression of these clustered miRNAs were significantly downregulated in PDAC cells (data not shown). Past studies demonstrated that $m i R-217$ were downregulated in

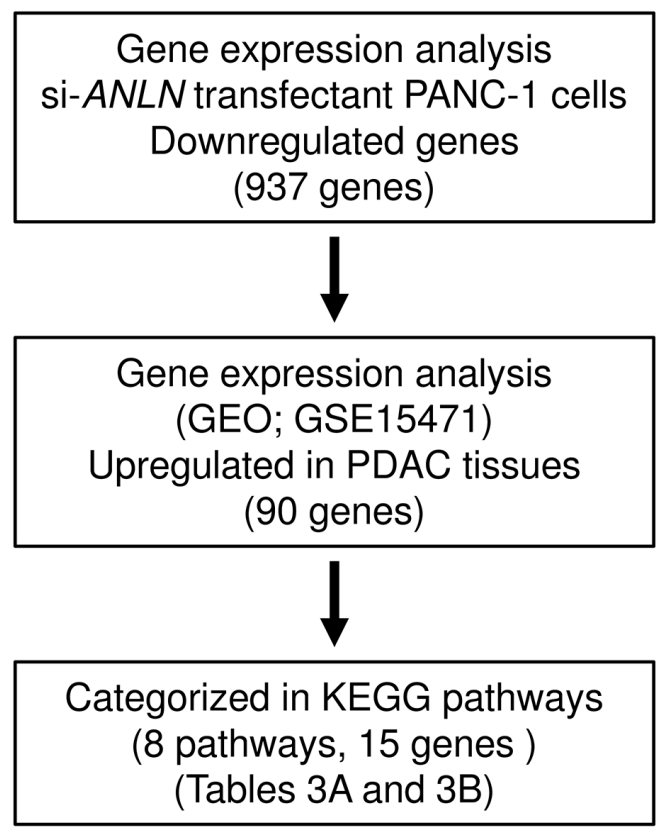

Figure 6: The strategy for analysis of $A N L N$ downstream genes. Flow chart illustrates the strategy for analysis of $A N L N$ mediated downstream pathways and genes in PDAC cells.
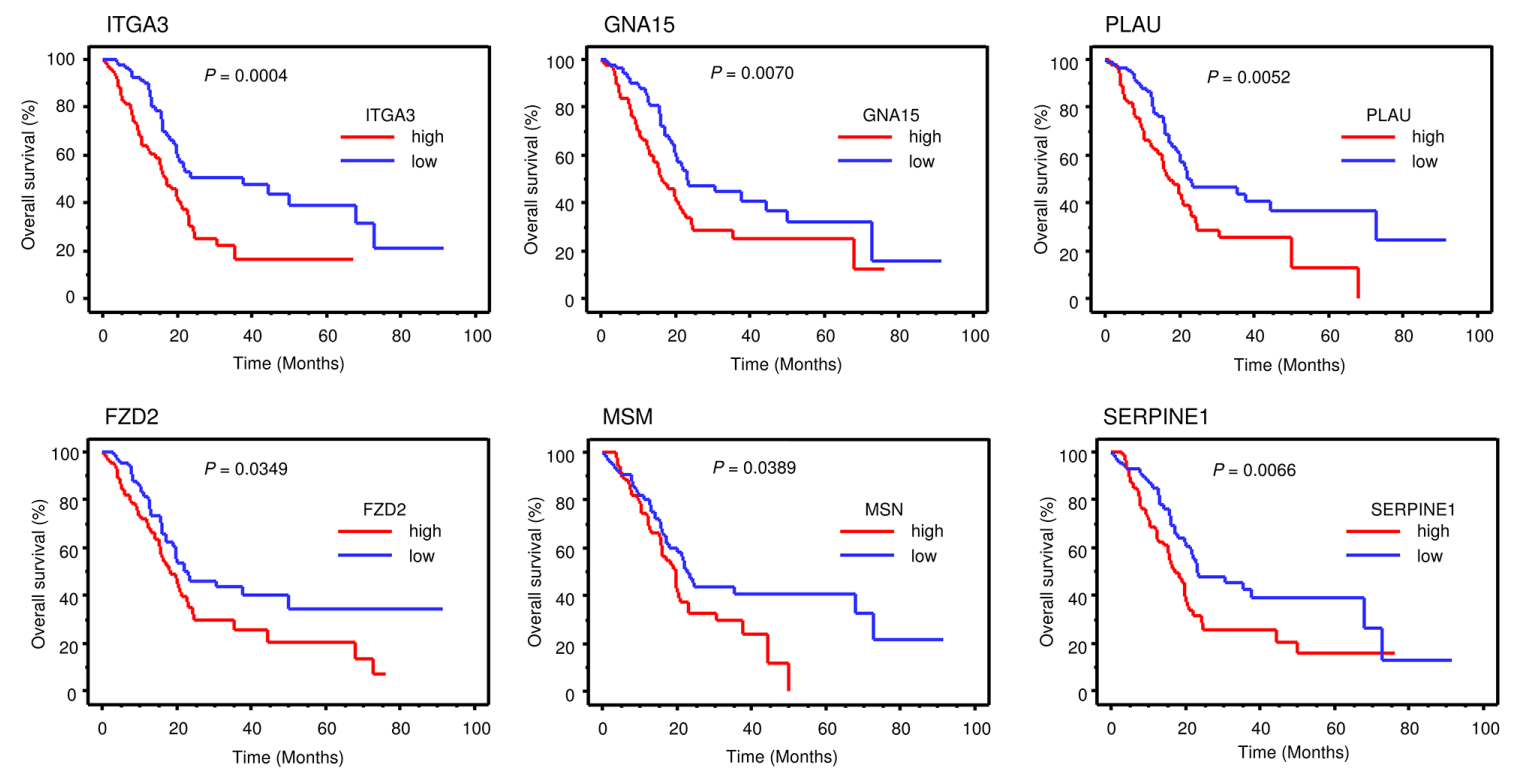

Figure 7: TCGA database analysis of $\boldsymbol{A N L} \boldsymbol{N}$ downstream genes. Kaplan-Meier plots overall survival with log-rank tests between those with high and low candidacy $A N L N$ downstream 6 genes expression in the PDAC TCGA database. 
esophageal adenocarcinoma cells and leukemia cells [27, 28]. Moreover, our data showed that these miRNAs acted as antitumor miRNAs in PDAC cells (data not shown). First, we combined genome-wide gene expression analysis and in silico database search to identify antitumor $m i R$ 217 targets in PDAC cells. Nineteen genes were identified as putative $m i R-217$ targets. Among them, we selected the actin-binding protein gene $A N L N$ because our past studies showed that several actin-binding protein genes (CORO1C, FSCN1,LASP1 and MSN) were overexpressed in cancer tissues and were deeply involved in promoting human cancer cell migration and invasion [29-32]. Interestingly, we showed that expression of these actinbinding proteins was regulated by several antitumor miRNAs (miR-1,miR-133a, miR-145 and miR-218) [33-36]. Our present data demonstrated that $A N L N$ was directly regulated by antitumor $m i R-217$ and knockdown of $A N L N$ significantly inhibited cancer cell aggressiveness in PDAC cells.

The human $A N L N$ gene was cloned as a human homologue of the Anln gene in Drosophila melanogaster that encodes a 1,125-amino acid actin-binding protein. ANLN has a unique multi-domain structure: an actinbinding and a myosin-binding domain at the $\mathrm{N}$-terminus and a pleckstrin homology domain at the C-terminus [37]. ANLN is a conserved protein implicated in cytoskeletal dynamics, and it is a ubiquitously expressed protein required for cytokinesis. ANLN is primarily located in the nucleus in interphase, whereas in telophase it relocates to the cytoplasm where it accumulates in the contractile ring and cleavage furrow [38]. A small guanosine triphosphatase, RHOA, interacts with ANLN and stabilizes actin-related proteins (F-actin, myosin, septins and $\mathrm{CD} 2 \mathrm{AP}$ ) in the cleavage furrow [39].

Overexpressed $A N L N$ was reported in several cancers and elevated expression appears to be involved in the metastatic potential of human cancers [23-25]. In non-small cell lung cancer (NSCLC), nuclear localization of ANLN was associated with poor survival of patients with NSCLC [40]. Likewise, detection of nuclear ANLN was significantly associated with decreased breast cancer survival and recurrence-free survival [41]. Our present immunohistochemical assessment of ANLN protein expression showed that ANLN was localized in cell nuclei in PDAC cells. Overexpression of $A N L N$ was confirmed in PDAC cells, and Kaplan-Meier survival curves showed that high expression of $A N L N$ predicted shorter survival in patients with PDAC by TCGA dataset analysis. Moreover, our data showed that reduced expression of $A N L N$ in PDAC cells suppressed cancer cell migration and invasion. Past studies showed that knockdown of $A N L N$ expression in breast cancer cells arrested the cell cycle in $\mathrm{S} / \mathrm{G} 2$ or G2/M transition [26]. These findings suggest that (1) ANLN has multiple functions, (2) its expression affects several oncogenic pathways and (3) overexpression of $A N L N$ enhances cancer cell aggressiveness.
To investigate the molecular pathways regulated by $A N L N$ in PDAC cells, we applied a genome-wide gene expression analysis using si- $A N L N$ transfectants. Our data showed that several pathways were downstream from $A N L N$, such as the "focal adhesion", "pathways in cancer", "ECM-receptor interaction" and "regulation of the actin cytoskeleton". Finally, we identified 15 genes that were upregulated in PDAC specimens and involved in those pathways. Among the 15 genes, high expression of ITGA3, GNA15, PLAU, FZD2, MSM and SERPINE1 predicted shorter survival in patients with PDAC as determined by TCGA database analysis. Our previous study showed that overexpression of ITGA3 enhanced cancer cell migration and invasion and directly regulated antitumor expression of $m i R-223$ in prostate cancer [42].

Integrins play an important role in cell adhesion by linking the cytoskeleton of cells to components in the extracellular matrix (ECM) by integrin-mediated signaling pathways [43]. Several studies show that dysregulated ECM-integrin signaling is implicated in the development and progression of cancer [44, 45]. A complex of PLAUR and its ligand PLAU is an important regulator of ECM proteolysis, ECM interactions and cell signaling [46]. In cancer, aberrant expression of PLAU and PLAUR has been linked to tumor progression, metastasis, and shortened survival in cancer [47-49]. These findings suggest that $m i R-217 / A N L N$-mediated genes are deeply involved in PDAC pathogenesis. However, the detailed molecular mechanism how downstream genes of $A N L N$ are regulated is still unclear. Future analysis is needed. Exploration of novel antitumor $m i R$-217-mediated pathways may lead to the development of new treatment protocols for this disease.

In conclusion, downregulation of $m i R-217$ was detected in PDAC clinical specimens. miR-217 acts as an antitumor miRNA through its targeting of $A N L N$ expression in PDAC cells. Expression of $A N L N$ enhanced cancer cell aggressiveness and its high expression predicts poorer survival of PDAC patients. Elucidation of $m i R$ 217/ANLN-mediated molecular networks may lead to a better understanding of PDAC pathogenesis and the development of new treatment protocols.

\section{MATERIALS AND METHODS}

\section{Clinical specimens and cell lines}

Clinical tissues specimens $(\mathrm{n}=27)$ were collected from patients with PDAC who underwent curative surgical resection at Kagoshima University Hospital between 1997 and 2015. Normal pancreatic tissue specimens $(n=14)$ were obtained from noncancerous tumor-adjacent tissue. Each surgical specimen was histologically classified according to the TNM classification system [50]. All patients in this study provided informed consent and the study protocol was approved by the Institutional Review 
Board of Kagoshima University. Two human PDAC cell lines were investigated in this study. PANC-1 cells were obtained from RIKEN Cell Bank (Tsukuba, Ibaraki, Japan) and SW 1990 cells were obtained from the ATCC (Manassas, Virginia, USA).

Total RNA, including miRNA, was isolated using ISOGEN (NIPPON GENE, Toyama, Japan) according to the manufacturer's protocol.

\section{Quantitative real-time PCR (qRT-PCR)}

Quantification of miRNA was performed using qRT-PCR as previously described [12, 13, 17, 51, 52]. Briefly, miRNAs were quantified using stem-loop RTPCR, TaqMan MicroRNA Assays and Assay-on-Demand Gene Expression TaqMan probes and primers as directed by the manufacturer. Probes and primers for $m i R-217$ (product ID: 002337; Thermo Fisher Scientific, Waltham, MA, USA), ANLN (product ID: Hs01122612_m1; Thermo Fisher Scientif), human GUSB (product ID: Hs99999908 $\mathrm{m} 1$; Thermo Fisher Scientific) and RNU48 (product ID: 001006; Thermo Fisher Scientific) were used as internal controls. Expression fold-changes were determined using the $\Delta \Delta \mathrm{Ct}$ method.

\section{Transfection of miRNA mimic and small interfering RNA (siRNA) into PDAC cell lines}

PDAC cell lines were transfected with a miRNA mimic for gain-of-function experiments and siRNA for loss-of-function experiments. Pre-miR ${ }^{\mathrm{TM}}$ miRNA precursors for $m i R-217$ (product ID: PM 12774), negative control miRNA (product ID: AM 17111), two ANLN siRNAs (product IDs: HSS122893 and HSS122895) and negative control siRNA (product ID: D-001810-10) were purchased from Thermo Fisher Scientific. The transfection efficiencies of miRNA in PANC-1 and SW 1990 cells were calculated as described in previous studies $[12,13$, $17,51,52]$.

\section{Cell proliferation, migration and invasion assays}

XTT assays were used to assess cell proliferation (Cell Proliferation Kit II, Roche Applied Sciences, Penzberg, Germany). Cell migration assays were performed with BD Falcon Cell Culture Inserts (BD Biosciences, Franklin Lakes, NJ, USA). Modified Boyden chambers containing Transwell-precoated Matrigel membrane filter inserts were used to quantitate cellular invasion. The protcols of these assays were described as previously $[12,13,17,51,52]$.

\section{Western blot analyses}

Protein lysates were collected $96 \mathrm{~h}$ after transfection and $20 \mu \mathrm{g}$ of protein were separated using gel electrophoresis on e-PAGEL 5-20\% gels (ATTO,
Tokyo, Japan) before transfer to polyvinylidene fluoride membranes. Solutions of mouse anti-ANLN antibodies (product ID: AMAb90662; Atlas Antibodies AB, Stockholm, Sweden) were diluted 1:750 for immunoblotting. Anti-GAPDH antibodies at a 1:1000 dilution (product ID: SAF6698; Wako, Osaka, Japan) were used as an internal loading control. A detailed description of the Western blotting procedure was published elsewhere $[12,13,17,51,52]$.

\section{Immunohistochemistry}

Tissue sections were incubated overnight at room temperature with anti-ANLN antibodies diluted 1:200 (product ID: AMA90662; Atlas Antibodies AB, Stockholm, Sweden). Overnight, antibodies were visualized using an avidin-biotin complex (ABC) detection kit (Vector Laboratories, Burlingame, CA, USA) and a diaminobenzidine substrate system according to the manufacturer's protocol. The expression of $A N L N$ was evaluated in cancer-rich fields using high-power microscopy $(400 \times)$.

\section{Genome-wide gene expression and in silico analyses}

To identify miR-217 target genes, we used in silico analyses conducted as described previously $[12,13,17$, 51, 52]. The microarray data were deposited into the GEO database (accession number GSE15471). Next, we selected putative miRNA target genes using the TargetScanHuman 7.1(June, 2016 release, http:/www. targetscan.org/vert_71) database and TCGA (The Cancer Genome Atlas, https://cancergenome.nih.gov/). Figure 2 shows the strategy for selecting target genes.

\section{TCGA database analysis of PDAC specimens}

The clinical significance of $A N L N$ in PDAC was assessed by RNA sequencing in TCGA OncoLnc (http:// www.oncolnc.org/) [53, 54]. We linked TCGA survival data to mRNA expression levels. We obtained clinical information on 174 PDAC samples from the National Cancer Institute CDC Data Portal (https://gdc-portal.nci. nih.gov/projects/TCGA-PAAD). We selected high and low $A N L N$ expression groups defined by the median value, and data were analyzed by Kaplan-Meier survival curves and log-rank statistics.

\section{Plasmid construction and dual-luciferase reporter assay}

The partial wild-type sequence of the $A N L N$ 3'-untranslated region (UTR) was inserted between the XhoI-PmeI restriction sites in the 3'-UTR of the hRluc gene in the psiCHECK-2 vector (C8021; Promega, Madison, WI, USA). Alternatively, we used sequences that 
were missing the miR-217 target sites (position 132 - 139 or position 660 - 666). The synthesized DNA was cloned into the psiCHECK-2 vector. PANC-1 and SW1990 cells were transfected with $20 \mathrm{ng}$ of the vector, $20 \mathrm{nM}$ microRNAs, and $1 \mu \mathrm{L}$ Lipofectamine 2000 (Invitrogen, Carlsbad, CA, USA) in $100 \mu \mathrm{L}$ Opti-MEM (Invitrogen). The procedure of dual-luciferase reporter assay was described previously [12, 13, 17, 51, 52].

\section{Identification of downstream targets regulated by $A N L N$ in PDAC}

We used genome-wide gene expression analysis in a PDAC cell line (PANC-1) transfected with si-ANLN. Genes downregulated by $A N L N$ were categorized by KEGG pathways using the GENECODIS program.

\section{Statistical analysis}

The relationships between 2 groups and expression values obtained by RT-qPCR were analyzed using the Mann-Whitney U-test. The correlation between expression of $m i R-217$ and $A N L N$ was evaluated using Spearman's rank test. The relationships among more than 3 variables and numerical values were analyzed using the Bonferroniadjusted Mann-Whitney U-test. Overall survival (OS) after surgery was gauged using Kaplan-Meier curves. Patients were divided into two groups based on $A N L N$ expression, and differences in survival were estimated using the logrank test. We used Expert StatView software (version 5.0 SAS Institute Inc., Cary, NC, USA) for these analyses [12, $13,17]$.

\section{ACKNOWLEDGMENTS}

We wish to thank the Joint Research Laboratory, Kagoshima University Graduate School of Medical and Dental Sciences, for the use of their facilities. The present study was supported by KAKENHI(C) grant 15K10801, $15 \mathrm{~K} 15501$ and 26293306.

\section{CONFLICTS OF INTEREST}

The authors declare no conflicts of interest.

\section{REFERENCES}

1. Chrystoja CC, Diamandis EP, Brand R, Ruckert F, Haun R and Molina R. Pancreatic cancer. Clin Chem. 2013; 59:41-46.

2. Kamisawa T, Wood LD, Itoi T and Takaori K. Pancreatic cancer. Lancet. 2016; 388:73-85.

3. Corbo V, Tortora G and Scarpa A. Molecular pathology of pancreatic cancer: from bench-to-bedside translation. Curr Drug Targets. 2012; 13:744-752.
4. Xu Z, Pothula SP, Wilson JS and Apte MV. Pancreatic cancer and its stroma: a conspiracy theory. World J Gastroenterol. 2014; 20:11216-11229.

5. Das S and Batra SK. Pancreatic cancer metastasis: are we being pre-EMTed? Curr Pharm Des. 2015; 21:1249-1255.

6. Zhang $Y$, Wang $Z$ and Gemeinhart RA. Progress in microRNA delivery. J Control Release. 2013; 172:962-974.

7. Bartel DP. microRNAs: target recognition and regulatory functions. Cell. 2009; 136:215-233.

8. Salmanidis M, Pillman K, Goodall G and Bracken C. Direct transcriptional regulation by nuclear microRNAs. Int $\mathrm{J}$ Biochem Cell Biol. 2014; 54:304-311.

9. Su Y, Li X, Ji W, Sun B, Xu C, Li Z, Qian G and Su C. Small molecule with big role: microRNAs in cancer metastatic microenvironments. Cancer Lett. 2014; 344:147-156.

10. Kita Y, Yonemori K, Osako Y, Baba K, Mori S, Maemura K and Natsugoe S. Noncoding RNA and colorectal cancer: its epigenetic role. J Hum Genet. 2017; 62:41-47.

11. Yonemori K, Kurahara H, Maemura K and Natsugoe S. MicroRNA in pancreatic cancer. J Hum Genet. 2016; 62:33-40.

12. Mataki H, Seki N, Mizuno K, Nohata N, Kamikawaji K, Kumamoto T, Koshizuka K, Goto Y and Inoue H. Dualstrand tumor-suppressor microRNA-145 (miR-145-5p and miR-145-3p) coordinately targeted MTDH in lung squamous cell carcinoma. Oncotarget. 2016; 7:7208472098. doi: 10.18632/oncotarget.12290.

13. Osako Y, Seki N, Kita Y, Yonemori K, Koshizuka K, Kurozumi A, Omoto I, Sasaki K, Uchikado Y, Kurahara H, Maemura K and Natsugoe S. Regulation of MMP13 by antitumor microRNA-375 markedly inhibits cancer cell migration and invasion in esophageal squamous cell carcinoma. Int J Oncol. 2016; 49:2255-2264.

14. Goto Y, Kojima S, Nishikawa R, Kurozumi A, Kato M, Enokida H, Matsushita R, Yamazaki K, Ishida Y, Nakagawa M, Naya Y, Ichikawa T and Seki N. MicroRNA expression signature of castration-resistant prostate cancer: the microRNA-221/222 cluster functions as a tumour suppressor and disease progression marker. $\mathrm{Br} \mathrm{J}$ Cancer. 2015; 113:1055-1065.

15. Goto Y, Kurozumi A, Nohata N, Kojima S, Matsushita R, Yoshino H, Yamazaki K, Ishida Y, Ichikawa T, Naya Y and Seki N. The microRNA signature of patients with sunitinib failure: regulation of UHRF1 pathways by microRNA-101 in renal cell carcinoma. Oncotarget. 2016; 7:59070-59086. doi: 10.18632/oncotarget.10887.

16. Koshizuka K, Nohata N, Hanazawa T, Kikkawa N, Arai T, Okato A, Fukumoto I, Katada K, Okamoto Y and Seki N. Deep sequencing-based microRNA expression signatures in head and neck squamous cell carcinoma: dual strands of pre-miR-150 as antitumor miRNAs. Oncotarget. 2017; 8:30288-30304. doi: 10.18632/oncotarget.16327.

17. Yonemori K, Seki N, Kurahara H, Osako Y, Idichi T, Arai T, Koshizuka K, Kita Y, Maemura K and Natsugoe 
S. ZFP36L2 promotes cancer cell aggressiveness and is regulated by antitumor microRNA-375 in pancreatic ductal adenocarcinoma. Cancer Sci. 2017; 108:124-135.

18. Guo J, Feng $\mathrm{Z}$, Huang $\mathrm{Z}$, Wang $\mathrm{H}$ and $\mathrm{Lu}$ W. MicroRNA-217 functions as a tumour suppressor gene and correlates with cell resistance to cisplatin in lung cancer. Mol Cells. 2014; 37:664-671.

19. Chen DL, Zhang DS, Lu YX, Chen LZ, Zeng ZL, He MM, Wang FH, Li YH, Zhang HZ, Pelicano H, Zhang W and Xu RH. microRNA-217 inhibits tumor progression and metastasis by downregulating EZH2 and predicts favorable prognosis in gastric cancer. Oncotarget. 2015; 6:10868-10879. doi: 10.18632/oncotarget.3451.

20. Zhang Q, Yuan Y, Cui J, Xiao T and Jiang D. MiR-217 promotes tumor proliferation in breast cancer via targeting DACH1. J Cancer. 2015; 6:184-191.

21. Zhao WG, Yu SN, Lu ZH, Ma YH, Gu YM and Chen J. The miR-217 microRNA functions as a potential tumor suppressor in pancreatic ductal adenocarcinoma by targeting KRAS. Carcinogenesis. 2010; 31:1726-1733.

22. Azevedo-Pouly AC, Sutaria DS, Jiang J, Elgamal OA, Amari F, Allard D, Grippo PJ, Coppola V and Schmittgen TD. miR-216 and miR-217 expression is reduced in transgenic mouse models of pancreatic adenocarcinoma, knockout of miR-216/miR-217 host gene is embryonic lethal. Funct Integr Genomics. 2016; 17:203-212.

23. Hall PA, Todd CB, Hyland PL, McDade SS, Grabsch H, Dattani M, Hillan KJ and Russell SE. The septin-binding protein anillin is overexpressed in diverse human tumors. Clin Cancer Res. 2005; 11:6780-6786.

24. Liang PI, Chen WT, Li CF, Li CC, Li WM, Huang CN, Yeh $\mathrm{HC}, \mathrm{Ke} \mathrm{HL}, \mathrm{Wu}$ WJ and Chai CY. Subcellular localisation of anillin is associated with different survival outcomes in upper urinary tract urothelial carcinoma. J Clin Pathol. 2015; 68:1026-1032.

25. Wang S, Mo Y, Midorikawa K, Zhang Z, Huang G, Ma N, Zhao W, Hiraku Y, Oikawa S and Murata M. The potent tumor suppressor miR-497 inhibits cancer phenotypes in nasopharyngeal carcinoma by targeting ANLN and HSPA4L. Oncotarget. 2015; 6:35893-35907. doi: 10.18632/ oncotarget.5651.

26. Zhou W, Wang Z, Shen N, Pi W, Jiang W, Huang J, Hu Y, Li X and Sun L. Knockdown of ANLN by lentivirus inhibits cell growth and migration in human breast cancer. Mol Cell Biochem. 2015; 398:11-19.

27. Nishioka C, Ikezoe T, Yang J, Nobumoto A, Tsuda M and Yokoyama A. Downregulation of miR-217 correlates with resistance of $\mathrm{Ph}(+)$ leukemia cells to ABL tyrosine kinase inhibitors. Cancer Sci. 2014; 105:297-307.

28. Xi S, Inchauste $\mathrm{S}$, Guo $\mathrm{H}$, Shan J, Xiao Z, Xu H, Miettenen M, Zhang MR, Hong JA, Raiji MT, Altorki NK, Casson AG, Beer DG, et al. Cigarette smoke mediates epigenetic repression of miR-217 during esophageal adenocarcinogenesis. Oncogene. 2015; 34:5548-5559.
29. Carmeci C, Thompson DA, Kuang WW, Lightdale $\mathrm{N}$, Furthmayr $\mathrm{H}$ and Weigel RJ. Moesin expression is associated with the estrogen receptor-negative breast cancer phenotype. Surgery. 1998; 124:211-217.

30. Darnel AD, Behmoaram E, Vollmer RT, Corcos J, Bijian K, Sircar K, Su J, Jiao J, Alaoui-Jamali MA and Bismar TA. Fascin regulates prostate cancer cell invasion and is associated with metastasis and biochemical failure in prostate cancer. Clin Cancer Res. 2009; 15:1376-1383.

31. Chiyomaru T, Enokida H, Kawakami K, Tatarano S, Uchida Y, Kawahara K, Nishiyama K, Seki N and Nakagawa M. Functional role of LASP1 in cell viability and its regulation by microRNAs in bladder cancer. Urol Oncol. 2012; 30:434-443.

32. Ren G, Tian Q, An Y, Feng B, Lu Y, Liang J, Li K, Shang Y, Nie Y, Wang X and Fan D. Coronin 3 promotes gastric cancer metastasis via the up-regulation of MMP-9 and cathepsin K. Mol Cancer. 2012; 11:67.

33. Chiyomaru T, Enokida H, Tatarano S, Kawahara K, Uchida Y, Nishiyama K, Fujimura L, Kikkawa N, Seki N and Nakagawa M. miR-145 and miR-133a function as tumour suppressors and directly regulate FSCN1 expression in bladder cancer. Br J Cancer. 2010; 102:883-891.

34. Kinoshita T, Nohata N, Fuse M, Hanazawa T, Kikkawa N, Fujimura L, Watanabe-Takano H, Yamada Y, Yoshino H, Enokida H, Nakagawa M, Okamoto Y and Seki N. Tumor suppressive microRNA-133a regulates novel targets: moesin contributes to cancer cell proliferation and invasion in head and neck squamous cell carcinoma. Biochem Biophys Res Commun. 2012; 418:378-383.

35. Nishikawa R, Goto Y, Sakamoto S, Chiyomaru T, Enokida H, Kojima S, Kinoshita T, Yamamoto N, Nakagawa M, Naya Y, Ichikawa $\mathrm{T}$ and Seki N. Tumor-suppressive microRNA-218 inhibits cancer cell migration and invasion via targeting of LASP1 in prostate cancer. Cancer Sci. 2014; 105:802-811.

36. Mataki H, Enokida H, Chiyomaru T, Mizuno K, Matsushita R, Goto Y, Nishikawa R, Higashimoto I, Samukawa T, Nakagawa M, Inoue H and Seki N. Downregulation of the microRNA-1/133a cluster enhances cancer cell migration and invasion in lung-squamous cell carcinoma via regulation of Coronin1C. J Hum Genet. 2015; 60:53-61.

37. Oegema K, Savoian MS, Mitchison TJ and Field CM. Functional analysis of a human homologue of the Drosophila actin binding protein anillin suggests a role in cytokinesis. J Cell Biol. 2000; 150:539-552.

38. Giansanti MG, Bonaccorsi S and Gatti M. The role of anillin in meiotic cytokinesis of Drosophila males. J Cell Sci. 1999; 112:2323-2334.

39. Gbadegesin RA, Hall G, Adeyemo A, Hanke N, Tossidou I, Burchette J, Wu G, Homstad A, Sparks MA, Gomez J, Jiang R, Alonso A, Lavin P, et al. Mutations in the gene that encodes the F-actin binding protein anillin cause FSGS. J Am Soc Nephrol. 2014; 25:1991-2002. 
40. Suzuki C, Daigo Y, Ishikawa N, Kato T, Hayama S, Ito T, Tsuchiya E and Nakamura Y. ANLN plays a critical role in human lung carcinogenesis through the activation of RHOA and by involvement in the phosphoinositide 3-kinase/AKT pathway. Cancer Res. 2005; 65:11314-11325.

41. Magnusson K, Gremel G, Ryden L, Ponten V, Uhlen M, Dimberg A, Jirstrom K and Ponten F. ANLN is a prognostic biomarker independent of Ki-67 and essential for cell cycle progression in primary breast cancer. BMC Cancer. 2016; 16:904.

42. Kurozumi A, Goto Y, Matsushita R, Fukumoto I, Kato M, Nishikawa R, Sakamoto S, Enokida H, Nakagawa M, Ichikawa T and Seki N. Tumor-suppressive microRNA-223 inhibits cancer cell migration and invasion by targeting ITGA3/ITGB1 signaling in prostate cancer. Cancer Sci. 2016; 107:84-94.

43. Gilcrease MZ. Integrin signaling in epithelial cells. Cancer Lett. 2007; 247:1-25.

44. Kinoshita T, Nohata N, Hanazawa T, Kikkawa N, Yamamoto $\mathrm{N}$, Yoshino $\mathrm{H}$, Itesako $\mathrm{T}$, Enokida $\mathrm{H}$, Nakagawa $\mathrm{M}$, Okamoto Y and Seki N. Tumour-suppressive microRNA29s inhibit cancer cell migration and invasion by targeting laminin-integrin signalling in head and neck squamous cell carcinoma. Br J Cancer. 2013; 109:2636-2645.

45. Hamidi H, Pietila M and Ivaska J. The complexity of integrins in cancer and new scopes for therapeutic targeting. Br J Cancer. 2016; 115:1017-1023.

46. Smith HW and Marshall CJ. Regulation of cell signalling by uPAR. Nat Rev Mol Cell Biol. 2010; 11:23-36.

47. Gorantla B, Asuthkar S, Rao JS, Patel J and Gondi CS. Suppression of the uPAR-uPA system retards angiogenesis, invasion, and in vivo tumor development in pancreatic cancer cells. Mol Cancer Res. 2011; 9:377-389.
48. Margheri F, Luciani C, Taddei ML, Giannoni E, Laurenzana A, Biagioni A, Chilla A, Chiarugi P, Fibbi G and Del Rosso M. The receptor for urokinase-plasminogen activator (uPAR) controls plasticity of cancer cell movement in mesenchymal and amoeboid migration style. Oncotarget. 2014; 5:1538-1553. doi: 10.18632/oncotarget. 1754.

49. Pavon MA, Arroyo-Solera I, Cespedes MV, Casanova I, Leon X and Mangues R. uPA/UPAR and SERPINE1 in head and neck cancer: role in tumor resistance, metastasis, prognosis and therapy. Oncotarget. 2016; 7:57351-57366. doi: 10.18632/oncotarget.10344.

50. Brierley JD, Gospodarowicz MK and Wittekind C. TNM Classification of Malignant Tumours, 7th Edition. Chichester, West Sussex, United Kingdom: WileyBlackwell; 2010.

51. Fukumoto I, Kinoshita T, Hanazawa T, Kikkawa N, Chiyomaru T, Enokida H, Yamamoto N, Goto Y, Nishikawa R, Nakagawa M, Okamoto Y and Seki N. Identification of tumour suppressive microRNA-451a in hypopharyngeal squamous cell carcinoma based on microRNA expression signature. Br J Cancer. 2014; 111:386-394.

52. Itesako T, Seki N, Yoshino H, Chiyomaru T, Yamasaki T, Hidaka H, Yonezawa T, Nohata N, Kinoshita T, Nakagawa $\mathrm{M}$ and Enokida $\mathrm{H}$. The microRNA expression signature of bladder cancer by deep sequencing: the functional significance of the miR-195/497 cluster. PLoS One. 2014; 9:e84311.

53. Anaya J. OncoRank: a pan-cancer method of combining survival correlations and its application to mRNAs, miRNAs, and lncRNAs. PeerJ Prepr. 2016; 1:e2574.

54. Anaya J. OncoLnc: linking TCGA survival data to mRNAs, miRNAs, and lncRNAs. PeerJ Comput Sci. 2016; 2:e67. 